tiến triển hoặc tử vong so với giả dược. Trung vị sự khác biệt PFS giữa 2 nhóm xấp xỉ 3 năm. Trung vị PFS ở những phụ nữ dùng giả dược là 13,8 tháng (tính từ thời điểm kết thúc hóa trị liệu), phù hợp với kết quả của các nghiên cứu sử dụng Paclitaxel + Carboplatin ở những phụ nữ mới được chẩn đoán UTBT tiến xa có đột biến gen BRCA. Sự cải thiện giá trị tuyệt đối PFS ở nhóm điều trị Olaparib so với giả dược trong nghiên cứu này cũng lớn hơn đáng kể so với những nghiên cứu sứ dụng thuốc ức chế PARP trong những trường hợp bệnh tái phát và một số người bệnh không phù hợp để dùng Olaparib như một biện pháp điều trị bước hai (ví dụ những người kháng Platinum). Nhiều bệnh nhân trong nghiên cứu này sau khi dừng can thiệp sau 2 năm đã không tiến triển bệnh trong nhiều tháng. Rõ ràng, chỉ có những bệnh nhân mới được chẩn đoán UTBT tiến xa, mới là nhóm bệnh nhẩn có khả năng chữa khỏi bệnh. Hầu hết người bệnh trong thử nghiệm này đều có đột biến gen BRCA1/2 dạng di truyền. Tuy nhiên, nhiều nghiên cứu khác cho thây: kết quả của can thiệp Olaparib có thể ứng dụng trên cả những người bệnh có đột biến BRCA1/2 mắc phải.

\section{KẾT LUÂNN}

Thử nghiệm SOLO1 đã cho thấy lợi ích đáng kể của Olaparib trong điều trị duy trì sau hóa trị liệu có Platinum, giúp cải thiện thời gian sống không bệnh tiến triển ở phụ nữ mới được chẩn đoán ung thư buồng trứng tiến xa có đột biến gen BRCA1/2.

\section{Tên viêt tắt:}

UTBT: Ung thư buồng trứng

HR: Hazard ratio - tỳ số nguy cơ

PARP: enzyme poly(adenosine diphosphate ribose) polymerase

OS: Overall Survival - Thời gian sống còn toàn bộ

PFS: Progression free survival - Thời gian sổng bệnh không tiến triển

RECIST 1.1: Response Evaluation Criteria In Solid Tumors version 1.1 - Tiêu chuẩn đánh giá đáp ứng khối u đă̆c bản 1.1

Tài liệu gốc: "Maintenance Olaparib in Patients with Newly Diagnosed Advanced Ovarian Cancer" Moore K et al. N. Engl. J. Med. 2018; 379:2495-505

Lời cảm ơn: Bài viết này được hố trợ từ AstraZeneca cho mục đích giáo dục y khoa.

\title{
THỰC TRẠNG KIẾN THỨC, THỰC HÀNH PHÒNG CHỐNG BÊNNH SỞI CỦA PHỤ NỮ MANG THAI TẠI THI XÃ TƯ SƠN, TỈNH BẮC NINH NĂM 2020 VÀ MộT SỐ YẾU TỐ LIÊN QUAN
}

\author{
Nguyễn Đăng Vững1, Trần Thanh Thủy ${ }^{1}$, Mai Thị Lan Hương ${ }^{2}$
}

\section{TÓM TẮT}

Điều tra mô tả cắt ngang trên 378 đối tượng tham gia nghiên cứu về kiến thức thực hành phòng chống bênh sởi của phụ nữ mang thai tại thi xã Từ Sơn, tỉnh Bẳc Ninh năm 2020 nhằm mô tả kiến thức và thực hành phòng chống bênh sởi của phụ nữ mang thai. Chọn mẫu theo phương pháp lập danh sách các đối tượing là phụ nữ có thai tai 4 xã, phường dựa trên sổ quản lý của cán bộ dân số và của chương trình chăm sóc sức khoẻ sinh sản từng xã, phường và điêuu tra toàn bộ số phụ nữ này. Kết quả nghiên cứu cho $94,2 \%$ đã nghe nói về bệnh sởi, chủ yếu từ nguồn thông tin đai chúng. $91 \%$ đối tượng biết bênnh sởi có khả năng lấy truyền; $85,4 \%$ biểt bệnh sởi lây theo đường hô hấp và 94,7\% đối tượng biết mức độ nguy

\section{${ }^{1}$ Trường Đại họ Y Hà Nọi,}

${ }^{2}$ TTYT thj xã Từ Sơn, Bắc Ninh

Chịu trách nhiệm chính: Nguyễn Đăng Vững

Email: vunghmu@gmai.com

Ngày nhận bài: 16.8.2021

Ngày phản biện khoa học: 18.10.2021

Ngày duyệt bài: 28.10.2021 hiểm của bênh sởi. Kiến thức phòng chống bệnh sởi của đối tượng nghiên cứu còn ở mức thấp, chỉ có 33,3\% đối tượng có kiến thức tốt. Kiến thức thực hành phòng chống bệnh sởi cũng chưa cao, chỉ có $23,8 \%$ các đối tượng có kiến thức thực hành tốt về phòng chống bệnh sởi.18,5\% đối tượng tham gia nghiên cứu có tiêm phòng sởi trước khi mang thai.

Từ khóa: Phụ nữ mang thai, bệnh sởi, Bắc Ninh.

\section{SUMMARY}

THE SITUATION OF KNOWLEDGE AND

PRACTICE FOR MEASURES PREVENTION OF MEPOSITIS OF PREGNANT WOMEN IN TU SON TOWN, BAC NINH PROVINCE 2020 AND SOME FACTORS

A cross-sectional descriptive survey is conducted on 378 subjects participating in the study on knowledge and practice of measles prevention among pregnant women in Tu Son town, Bac Giang province in 2020. Select subjects by using the method of making a list of pregnant women in 4 communes and wards, based on the management books of population officials and the reproductive health care program of each commune and ward and survey these women. 
Research results show that $94.2 \%$ had heard of measles, mainly from mass media sources. $91 \%$ of subjects knew measles was contagious; $85.4 \%$ knew that measles was transmitted by the respiratory system and $94.7 \%$ of subjects knew the danger level of measles. The study shows that subjects' knowledge of measles prevention was still low, only $33.3 \%$ of the subjects had good knowledge. Knowledge and practice of measles prevention is also not high, with only $23.8 \%$ of the subjects had good understanding. $18.5 \%$ of the study participants had measles vaccination before pregnancy.

Keywords: Pregnant women, measles, Bac Giang.

\section{I. ĐặT VẤN ĐỀ}

Sởi là bênh truyền nhiễm cấp tính với khả năng lây nhiê̂m cao, có thể gây ra các biên chứng nặng nề và gây tử vong đặc biệt ở trẻ nhỏ. Trước đây, bệnh xảy ra thường xuyển và có tỷ lệ lây nhiếm cũng như tử vong cao. Theo Tổ chức Y tế Thễ giới, trước khi có vắc xin, khoảng $90 \%$ số người bị mắc sởi trước 20 tuổi ${ }^{1}$.

Tại Việt Nam, vắc xin sởi được sử dụng trong Chương trình tiêm chủng mở rộng tại Việt Nam từ 1985. Vắc xin sởi, rubella được sử dụng từ 2014 trong chiến dịch tiêm Sởi-Rubella và đưa vào tiêm chủng thường xuyên lúc 18 tháng vào năm $2015^{3}$. Tuy nhiên bệnh sởi vẫn là một trong những nguyên nhân hàng đầu gây tử vong ở trẻ nhỏ trên toàn cầu, mặc dù đã có vắc xin an toàn và hiệu quả trong nhiêu năm nay. Khoảng 89.790 người đã chết vì bệnh sởi năm 2016 chủ yêu là trẻ em dưới 5 tuôiit. Năm 2017 trên địa bàn toàn thị xã Từ Sơn chỉ có 2 trường hợp mắc sởi, tuy nhiên đễn năm 2018 tăng lên 15 trường hợp mắc, đặc biệt trong đó có tới 14/15 trường hợp là trẻ em từ $0-5$ tuổi. Và gần đây nhất là nămm 2019 số trường hợp mắc tăng lên 59 trong đó có 28 trường hợp là trẻ em từ 0-5 tuổi Trên thực tế, mặc dù bệnh sởi có thể có những biến chứng nặng nề, dẫn tới tử vong nhưng nếu được phát hiện sớm, chăm sóc và điều trị kịp thời thì bênh có thể khỏi và tránh được các biển chứng. Vậy người dân, đặc biệt phụ nữ mang thai có kiển thức như thế nào về phòng chông bệnh sởi, có bao nhiêu phụ nữ đã tiêm phòng trước khi mang thai và có những yếu tố nào ảnh hưởng đến kiến thức và thực hành phòng chống bệnh sởi? Từ Sơn là một đồ thị công nghiệp với nhiều khu công nghiệp, nhiều làng nghề truyền thống nổi tiêng, đặc điểm dân cư ở đây khá phức tạp do có nhiều đối tượng tạm trú trên địa bàn'. Do đó tiềm ẩn các nguy cơ bùng phát ổ dịch sởi trên địa bàn, chính vì vậy, tôi thực hiện đề tài: Thực trạng kiến thức, thực hành phòng chống bệnh sởi của phụ nữ mang thai tại Thị xã
Từ Sơn, tỉnh Băc Ninh năm 2020 và một số yêu tố liên quan.

II. ĐỐI TƯợNG VÀ PHƯƠNG PHÁP NGHIÊN CỨU

Đối tượng nghiên cứu: Phụ nữ có thai tại địa bàn thị xã Từ Sơn trong khoảng thời gian nghiên cứu.

Thời gian nghiên cứu: Tháng 3/2020 đến tháng 11/2020,

\section{- Địa điểm nghiên cứu}

Địa điểm: Tại 4 xã, phường Tân Hồng, Hương Mạc, Tam Sơn, Đồng Nguyên - thị xã Từ Sơn tỉnh Bắc Ninh.

Thiết kế nghiên cứu: Nghiên cứu mô tả cắt ngang

- Cỡ mẫu: Toàn bộ số phụ nữ có thai tại 4 xã, phường trên địa bàn thị xã Từ Sơn trong khoảng thời gian nghiên cứu. Cõ̃ mẫu thu thập được tại thời điểm nghiên cứu là 378 đối tượng phụ nữ có thai.

\section{Phương pháp chọn mẫu:}

Chọn xã: trong sổ 12 xã, phường tại Thị xã Từ Sớn chọn 4 xã, phường có tính đại diện về vị trí địa lý, đặc điểm kinh tế. Sau khi đã் chọn được 4 xã, phường làm địa điểm nơi tiến hành nghiển cứu, lập danh sách các đối tượng là phụ nữ có thai tại 4 xã, phường dựa trên sổ quản lý của cán bộ dân số và của chương trình chăm sóc sức khoẻ sinh sản từng xã, phường và điều tra toàn bộ số phụ nữ này.

Kỹ thuật và công cư thu thập số liệu:

Bộ câu hỏi đánh giá kiến thức, thực hành phòng chống bệnh sởi, bao gồm 3 phần chính:

+ Đặc điểm của đối tượng nghiên cứu: tuổi, số con hiện có, địa bàn sinh sống, tình trạng hôn nhân, trình độ học vấn, nghề nghiêp, hoàn cảnh kinh tế.

+ Phần kiễn thức gồm các câu hỏi về kiến thức chung về bệnh sởi, các biện pháp phòng chống bệnh sởi, nguồn cung cẩp thông tin về bệnh sởi; cách chăm sóc, phòng ngừa khi mắc sởi.

+Phần thực hành gồm các nội dung Thực hành tiêm phòng cho bản thân trước khi mang thai; Thực hành tiêm phòng cho con (đối với đối tượng đã có $\geq 1$ con).

Bộ câu hỏi được xây dựng, chỉnh sửa bổ sung cho phù hợp với mục tiêu nghiên cứu dựa trên nghiên cứu của Lê Hồng Trường (2014), Đoàn Văn Dương (2017) ${ }^{7}$ và Quyết định số 4845/QĐBYT ngày 05/12/2012 của Bộ trưởng Bộ $Y$ tế về việc "Hướng dẫn giám sát và phòng chổng bệnh sởi, rubella". Bộ câu hỏi đã được thử nghiệm trên 18 phụ nữ có thai tại xã Tam Sơn. Sau khi điều tra thử có chỉnh sửa, bổ sung cách phỏng vân và hướng dẫn trả lời câu hỏi cho phù hợp 
với mục tiêu, nội dung nghiên cứu.

Lập danh sách các đối tượng là phụ nữ có thai trong thời gian nghiên cứu tại 4 xã, phường đã được chon.

- Theo danh sách đã lập tiến hành phỏng vấn trực tiếp các phụ nữ mang thai đến khám thai và tiểm chủng tại TYT xã/phường vào các ngày nhất định trong tháng, còn các phụ nữ mang thai còn lại nhóm nghiên cứu sẽ đến từng nhà của đối tượng để tiến hành phỏng vấn trực tiếp cho đến hểt danh sách.

- Thời gian phỏng vấn từ tháng $5 / 2020$ đến 7/2020, đối với các phụ nữ mang thai không đên khám thai và tiêm chủng, nhóm NC gọi điện hoặc sắp xếp lịch trước (nhờ cộng tác viên khu phố/thôn/xóm) khi đến nhà đổi tượng để đảm bảo đối tượng có mặt tại nhà thời điểm đến phỏng vấn.

- Tiếp cận và phỏng vấn đối tượng theo quy trình: chào hỏi, giới thiệu về mục đích nghiên cứu và phỏng vấn.

- Điều tra viên gồm 4 cán bộ Khoa Kiểm soát bệnh tật và HIV/AIDS - Trung tâm $Y$ tế thị xã và 4 cán bộ Trạm $Y$ tế của 4 xã, phường được đào tạo và tập huấn bài bản về kỹ năng và bộ công cụ, ngoài ra phối hợp thêm các cộng tác viên khu phố/thôn/xóm để quá trình thu thập số liệu tại nhà được tiến hành nhanh chóng, hiệu quả. Thành lập 04 tổ điều tra/ 4 xã, phường. Mỗi tổ bao gồm: 01 cán bộ Trung tâm $Y$ tế, 01 cán bộ Trạm $Y$ tế và các cộng tác viên của từng khu phố/thôn/xóm.

\section{Xử lý và Phân tích số liệu:}

- Số liệu điều tra được kiểm tra, làm sạch các lỗi, mã hóa và nhập thông tin vào máy tính bằng phần mềm EpiData 3.1. Số liệu được phân tích bằng phần mềm SPSS 20.0.

Phân tích hồi quy logistic bằng mô hình Stepwise phân tích mối liên quan giữa một số yếu tố liên quan với kiến thức và thực hành phòng chống bệnh sởi.

Đạo đức nghiên cứu. Đối tượng được mời tham gia vào nghiên cứu được giải thích cụ thể về mục đích, nội dung nghiên cứu và dựa trên nguyển tắc đồng thuận tham gia nghiên cứu.

- Mọi thông tin của đối tượng đều được giữ bí mật và chỉ sử dụng cho mục đích nghiên cứu.

- Đề tài đã được sự chấp thuận của địa phương và Trung tâm $Y$ tế thị xã Từ Sớn.

- Đề tài đã được Hội đồng thông qua đề cương của trường Đại học Y Hà Nội phê duyệt.

\section{KẾT QUẢ NGHIÊN CứU}

\section{Bảng 3.1: Phân bố đổi tượng nghiên cứu theo tuổi và tình trạng cư trú}

\begin{tabular}{|c|c|c|c|c|c|c|}
\hline \multirow{3}{*}{ Nhóm tuổi } & \multicolumn{4}{|c|}{ Tình trạng cư trú } & \multirow{2}{*}{\multicolumn{2}{|c|}{ Cộng }} \\
\hline & \multicolumn{2}{|c|}{ Thường trú } & \multicolumn{2}{|c|}{ Tạm trú } & & \\
\hline & SL & $\%$ & SL & $\%$ & SL & $\%$ \\
\hline$<30$ tuối & 218 & 57,7 & 36 & 9,5 & 254 & 67,2 \\
\hline$\geq 30$ tuối & 114 & 30,2 & 10 & 2,6 & 124 & 32,8 \\
\hline Tống & 332 & 87,9 & 46 & 12,1 & 378 & 100 \\
\hline
\end{tabular}

Trong tống số 378 đối tượng tham gia nghiên cứu có 254 đối tượng có tuối < 30 tuổi chiếm $67,2 \%$ và có 124 đối tượng từ 30 tuổi trở lên chiếm 32,8\%. Trong đó, số đối tượng thường trú tại địa bàn chiếm tỷ lệ $87,9 \%$, còn lại là đối tượng tạm trú chiếm 12,1\%.

Bảng 3.2. Kiến thức về khả năng lây truyền và đường lây truyền bệnh sởi

\begin{tabular}{|c|c|c|}
\hline Nội dung & SL & $\%$ \\
\hline Bệnh sởi có lây truyền không & & \\
Có & 344 & 91 \\
Không & 18 & 4,8 \\
Không biết & 16 & 4,2 \\
\hline Tống & 378 & 100 \\
\hline Đường lây & & \\
Hô hấp & 323 & 85,4 \\
Tiêu hoá & 12 & 3,2 \\
Máu & 17 & 4,5 \\
Da, niêm mạc & 26 & 6,9 \\
\hline Tống & 378 & 100 \\
\hline
\end{tabular}

Nhìn chung số đối tượng hiểu đúng về khả năng lây truyền và đường truyền của bệnh sởi

cao, có $91 \%$ đối tượng trả lời đúng câu hỏi bệnh sởi có lây truyền không và $85,4 \%$ đối tượng trả lời đúng đường lây của bệnh sởi là đường hô hấp.

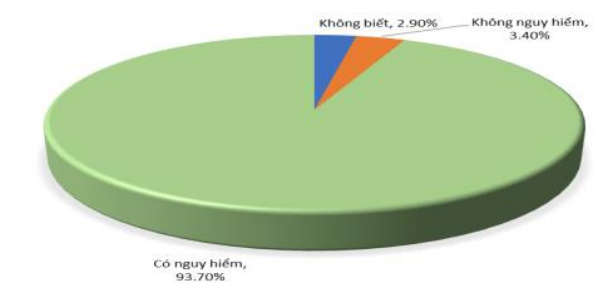

Biểu đồ 3.1. Kiến thức về mức độ nguy hiểm của bênh sởi

Trong tổng số 378 đối tượng nghiên cứu có 
354 đối tượng trả lời bệnh sởi có nguy hiểm chiếm tỷ lệ $93,7 \%$, chỉ có 13 đối tượng 3,4\% trả lời không nguy hiểm $(3,4 \%)$ và 11 đối tượng trả lời không biết mức độ nguy hiểm của bệnh sởi $(2,9 \%)$.

Trong 378 đối tượng nghiên cứu có 2 triệu chứng là sốt và phát ban được lựa chọn trả iời đúng nhiều nhất với tỷ lệ lần lượt là $98,4 \%$ và $96,6 \%$. Trong khi đó cũng có rất nhiều những kiến thức về triệu chứng của bệnh mà các đối tượng trả lời khồng biết khá cao như hạt koplic, đau khớp, sưng hạch sau tai, viêm kết mạc với tý lệ lần lượt là $66,1 \%, 54,2 \%, 48,9 \%, 43,2 \%$.
Kiến thức thực hành về phòng chống bệnh sởi

Bảng 3.3. Nơi điều trị cho trẻ nếu trẻ bị sởi

\begin{tabular}{|c|c|c|}
\hline Địa điếm & SL & $\mathbf{\%}$ \\
\hline Bệnh viện & 250 & 66,1 \\
\hline Phòng khám tư nhân & 7 & 1,9 \\
\hline Tống & $\mathbf{3 7 8}$ & $\mathbf{1 0 0}$ \\
\hline
\end{tabular}

Trong tống số 378 đối tượng nghiên cứu có tới $66,1 \%$ các bà mẹ lựa chọn nơi điều trị là bệnh viện, tiếp đến là trạm y tể xã với tỷ lệ 32\%. Chỉ có $1,9 \%$ các bà me lựa chọn cho con đi phòng khám tư nhân và̀ không có ai tự mua thuốc về nhà điều trị khi con bị mắc sởi.

Bảng 3.4. Thực hành các biện pháp phòng bệnh sởi $(n=378)$

\begin{tabular}{|c|c|c|c|c|c|c|}
\hline \multirow{3}{*}{ Biện pháp } & \multicolumn{6}{|c|}{ Thực hành } \\
\hline & \multicolumn{2}{|c|}{ Đúng } & \multicolumn{2}{|c|}{ Sai } & \multicolumn{2}{|c|}{ Không biết } \\
\hline & $\mathbf{S L}$ & $\%$ & SL & $\%$ & SL & $\%$ \\
\hline Với trẻ còn bú mẹ, cần cho bú càng nhiều càng tốt & 316 & 83,6 & 35 & 9,3 & 27 & 7,1 \\
\hline Tiêm vắc xin cho bà me chuân bi mang thai & 256 & 67,7 & 12 & 3,2 & 110 & 29,1 \\
\hline Tiêm vắc xin cho trẻ khi đủ 9 tháng & 330 & 87,3 & 3 & 0,8 & 45 & 11,9 \\
\hline $\begin{array}{c}\text { Tránh tiếp xúc với trẻ bênh trong vòng ít nhất } 4 \text { ngày } \\
\text { sau khi xuất hiện các vết ban }\end{array}$ & 222 & 58,7 & 42 & 11,1 & 114 & 30,2 \\
\hline Cho trẻ ăn đây đủ chất dinh dưỡng & 366 & 96,8 & 4 & 1,1 & 8 & 2,1 \\
\hline Giữ gìn vệ sinh cho trẻ & 372 & 98,4 & 0 & 0 & 6 & 1,6 \\
\hline
\end{tabular}

Thực hành đúng được các bà mẹ lựa chọn nhiều nhất là giữ gìn về sinh cho trẻ chiếm tỷ lệ $98,4 \%$, lựa chọn ít nhất là tiránh tiếp xúc với trẻ bệnh trong vòng ít nhất 4 ngày sau khi xuất hiện các vết ban với tỷ lệ $58,7 \%$. Trong khi đó có 2 biện pháp thực hành được các bà me trả lời không biết nhiều nhất là Tiêm vắc xin cho bà me chuẩn bị mang thai và Tránh tiếp xúc với trẻ bệnh trong vòng ít nhất 4 ngày sau khi xuất hiện các vết ban với tỷ lệ lần lượt là $29,1 \%$ và $30,2 \%$.

\section{BÀN LUÂ̂N}

Bênh sởi có tính lây truyền rất cao, thời gian ủ bệnh (từ ngày phơi nhiễm đến ngày phát ban) trung bình từ 14-15 ngày (dao động từ 7-18 ngày). Thời kỳ lây nhiễm vi rút xuất hiện từ cuối giai đoạn ủ bệnh tương ứng với khoảng thời gian 4 ngày trước đến 4 ngày sau khi xuất hiện ban. Do đó để phòng, chổng được bệnh các bà mẹ cần có những kiến thức cơ bản để nhận biết sớm các trường hợp mắc bệnh, đặc biệt là những trường hợp nghi ngờ mắc bệnh. Việc phát hiện bệnh sớm đóng vai trò rất lớn trong việc điều trị bệnh và ngăn chặn dịch tại cộng đồng. Chúng tôi nhận thấy rằng nhìn chung số đối tượng hiểu đúng về khả năng lây truyên và đường truyền của bệnh sởi khá cao, có $91 \%$ đối tượng trả lời đúng câu hỏi bệnh sởi có lây truyền không và $85,4 \%$ đối tượng trả lời đúng đường lây của bệnh sởi là đường hô hấp. Trong khi đó có 4,8\% đối tượng cho rằng bệnh sởi không lây truyền và 4,2\% trả lời là không biết bệnh sởi có lây truyền hay là không. Về đường lây vẫn còn $6,9 \%$ đối tượng trả lời rằng bệnh sởi lây qua $\mathrm{Da}$, niêm mạc; $4,5 \%$ trả lời lây qua đường máu và $3,2 \%$ lây qua đường tiêu hoá. Trong tổng số 378 đối tượng nghiên cứu có $94,7 \%$ đối tượng trả lời bệnh sởi có nguy hiểm, chỉ có 3,4\% trả lời không nguy hiểm và $2,9 \%$ trả lời không biết mức độ nguy hiểm của bệnh sởi. Kết quả này cao hơn kết quả nghiên cứu của Đoàn Văn Dương (2016), số bà me cho rằng bệnh sởi rất nguy hiểm chiếm tỷ lệ $83,2 \%{ }^{6}$. Phần lớn các đối tượng nghiên cứu đã nhận thức được mức độ nguy hiểm của bệnh sởi và có tỷ lệ cao hơn các nghiên cứu trước có thể là do hiện nay hàng năm đều tổ chức chiến dịch tiêm bổ sung sởi - rubella cho trẻ từ $1-5$ tuổi và công tác tuyên truyền trên các kênh đều được triển khai rộng rãi giúp các đối tượng dễ dàng tiếp cận thông tin hơn rất nhiều. Từ đó nhận thức được mức độ nguy hiểm của bệnh sởi. có $50,3 \%$ bà me biết bệnh sởi có khả nẳng lây truyền cao; $69 \%$ bà mẹ biết tiêm vắc xin sởi sẽ phòng được bệnh; Vi rút sởi lây theo đường hô hấp $(56,1 \%) ; 47 \%$ bà me cho rằng bệnh sởi chủ yếu gặp ở trẻ em dưới 10 tuổi, thường gặp ở trẻ em dưới 5 tuổi; $18 \%$ bà mẹ biết miễn dịch của mẹ truyền cho trẻ có thể bảo vệ trong khoảng 6-9 tháng ${ }^{7}$. Theo Lê Hồng Trường (2014) có 39,2\% bà mẹ biết bệnh có khả 
năng lây truyền cao; $52,2 \%$ biết tiêm vắc xin sởi có thể phòng được bệnh; $34,0 \%$ bà me biết miễn dịch của mẹ truyền cho trẻ có thể bảo vệ trong khoảng 6-9 tháng ${ }^{4}$.

Đồng thời qua nghiên cứu này cũng cho biết vẫn còn nhiều đối tượng tham gia nghiên cứu trả lời không biết về những hiểu biết về bệnh sởi, kiến thức trả lời không biết nhiều nhất là Miễn dịch của mẹ truyền cho trẻ có thể bảo vệ trong khoảng 6-9 tháng chiếm tỷ lệ 27,2\%. Trẻ dưới 9 tháng tuổi là trẻ chưa đến tuổi tiêm chủng vắc xin sởi. Vì thông thường trẻ dưới 9 tháng tuổi được bảo vệ bởi kháng thể của mẹ truyền sang con. Do đó, trẻ trong giai đoạn tuổi này có thể bị nhiễm sởi bởi các lý do như: Thứ nhất, nếu bà me của những trẻ này chưa có miễn dịch với sởi (chưa bị sởi, chưa tiêm phòng sởi, hoặc miễn dịch sởi yếu do tiêm vắc xin sởi không đủ đáp ứng) thì trẻ sinh ra sẽ không có miễn dịch sởi; thứ hai là me có miễn dich sởi nhưng khổng cho con bú; thứ ba là hệ miễn dịch của trẻ không đủ duy trì nồng độ kháng thể trong thời gian dài. Do đó, ở nhóm trẻ dưới 9 tháng tuổi vẩn gặp mắc sởi với một tỉ lệ nhất định. Việc phát hiện sớm và điều trị kịp thời đóng vai trò quan trọng để ngăn chặn những biến chứng do sởi gây ra, đồng thời có biện pháp cách ly, ngăn chặn việc lây lan thành dịch bênh. Theo kết quả nghiên cứu giám sát của viện Vệ sinh dịch tễ Trung ương năm 2013, tỉ lệ trẻ mắc bệnh sởi trong số các trường hợp có sốt phát ban nghi sởi rất cao trên $70 \%^{3}$.

\section{KẾT LUÂ̂N}

94,2\% đã nghe nói về bệnh sởi, chủ yếu từ nguồn thông tin đại chúng. $91 \%$ đối tượng biết bệnh sởi có khả năng lây truyền; $85,4 \%$ biết bệnh sởi lây theo đường hô hấp và $94,7 \%$ đối tượng biết mức độ nguy hiểm của bệnh sởi. Kiến thức phòng chống bệnh sởi của đối tượng nghiên cứu còn ở mức thấp, chỉ có 33,3\% đối tượng có kiến thức tốt. Kiến thức thực hành phòng chống bênh sởi chưa cao, chỉ có $23,8 \%$ các đối tượng có kiến thức thực hành tốt về phòng chống bệnh sởi. 18,5\% đối tượng tham gia nghiên cứu có tiêm phòng sởi trước khi mang thai.

\section{TÀI LIỆU THAM KHẢO}

1. Bô Y Y tế. Cẩm nang phòng chống bênh truyền nhiễm. Bệnh Sởi, Hà Nội, 2009; 222-8

2. WHO. Weekly Epidemiologitrường hợpl Record. 2009

3. Viện vệ sinh Dịch tề Trung ương: Tổng kết Tiểm chủng mở rộng năm 2014. Dự án tiêm chủng mở rộng. 2015

4. WHO. Measles Fact sheet 2017 [18/02/2018] http://www.who.int/mediacentre/Factsheets/fs286/en/

5. Leuridan $E$, Hens $N$, Hutse $V$, Leven $M$, Van Damme P. Early waning of maternal measles antibodies in era of measles elimination: longitudinal study. BMJ, 2010; 340: 1-7. Francis L.Black (1966), "Measles", Springer, tr. 397-398.

6. Trung tâm Y tế thị xã Từ Sơn: Báo cáo tổng kết năm 2018, 2019.

7. Đoàn Văn Dương. Thức trang dich sởi, công tác đáp ứng phòng chống dịch và̀ kiến thức, thực hành của bà me về bệnh sởi tại 5 xã của huyện Ngọc Lăc, tỉnh Thanh Hóa năm 2016. Luân văn thạc sĩ Y tể công công, Trường Đại học Y Dược Thái Bình. 2017

8. http://tuison.bacninh.gov.vn

9. Herch BS, Olive JM và CS, "Meales elimination in the Ameritrường hợps: evolving strategies". JAMA, 1996; 275 (3): 224 - 229.

\section{ĐÁNH GIÁ NỒNG Độ ACID URIC MÁU Ở BÊNH NHÂN VIÊM THẬN LUPUS VÀ MộT SỐ YẾU TỐ LIÊN QUAN}

\section{TÓM TẮT}

Mục tiêu: Khảo sát nồng độ acid uric máu ở bệnh nhân viêm thận Lupus và tìm hiểu mối liên quan giữa tăng acid uric máu và một số yếu tố lâm sàng và cận lâm sàng ở nhóm bệnh nhân. Đối tượng và phươning pháp nghiên cứu: Nghiên cứu mô tả cắt ngang, hồi cứu và tiến cứu trên 117 bệnh nhân viêm thận lupus

\footnotetext{
${ }^{1}$ Trường Đại Học Y Hà Nội

${ }^{2}$ Tt Thận - tiết niệu và Lơc máu, Bệnh viện Bạch Mai Chịu trách nhiệm chính: Nguyễn Thị Lệ Mỹ

Email: nguyenthilemy19121995@gmail.com

Ngày nhận bài: 20.8.2021

Ngày phản biên khoa hoc: 19.10.2021

Ngày duyệt bài: 29.10.2021
}

\section{Nguyễn Thị Lệ Mỹ', Đặng Thị Việt Hà ${ }^{1,2}$, Đỗ Gia Tuyển 1,2}

điều trị tại Trung tâm Thận - Tiết niệu và lọc máu bệnh viện Bạch Mai từ tháng 01/2020 đến 08/2021. Kết quả: 117 bênh nhân nghiên cứu có tuổi trung bình là $34.6 \pm 1.11$, với tỷ lệ nam/nữ là $1 / 9.64$ và $35.9 \%$ bệnh nhân phát hiện bệnh trong 1 tháng. Tỷ lệ tăng acid uric máu chiếm $75.2 \%$, nồng độ trung bình là $463.60 \pm 1.03$. Tỷ lệ tăng acid uric ở nữ cao hơn nam có ý nghĩa thống kê $(p<0.01)$ nhưng nồng độ acid uric ở 2 giới thì không có sự khác biệt $(p>0.05)$. Các triệu chứng như tràn dịch màng tim (57.7\%), tăng huyết áp (56.4\%), hôi chứng thân hư (57.3\%) thiếu máu $(87.2 \%)$ có sự khác biệt có ý nghĩa thống kê giữa 2 nhóm tăng acid uric và không tăng acid uric $(p<0.05)$. Trên sinh thiết thận ở 46 bệnh nhân, tỷ lệ class III, IV là $30.6 \%, 61.1 \%$, nồng độ acid uric trung bình: $415.18 \pm 102.025$ và $503.76 \pm 105.190$, có sự khác 